\title{
Poison in the Frying Pan
}

\author{
Rudrajit Paul
}

\section{Abstract}

Food adulteration causes a lot of adverse health effects. The author here describes an acute public health emergency caused by adulteration of edible oil in the 1980s. The victims suffered from permanent disability.

Keywords: Kolkata, Neuropathy, Poisoning, Rapeseed oil.

Bengal Physician Journal (2019): 10.5005/jp-journals-10070-6120

\section{INTRODUCTION}

Food adulteration is nothing new to India. While dishonest traders who would like to make a quick buck are the driving forces behind this crime, the consumers in India are also not aware of their right to purity and quality. Adulteration does not only mean addition of unwanted substances to food but also mean removal of certain ingredients from food, as the next example will show. Many of the spices used in daily Indian cooking are adulterated, like colored sawdust mixed with chilli powder, cassia bark added to cinnamon, or the essential oil taken out of cardamom or cloves. In 2015, a small survey done in Northern India before Diwali found that almost $90 \%$ of the sweets and other popular food items for the festival were adulterated and harmful for the human body.

Recent survey reports have indicated that many of the food items available in the Indian market are grossly substandard and have various adulterants added to them. For example, items like tomato sauce, turmeric powder, and tea powder have added colors. In another recent survey, it was found that more than two thirds of the milk sold in India is not suitable for human consumption with various substances like detergent or white paint used for adulteration. However, in most cases, the adulteration of food is a slow process, and acute effects are not discernible. Thus, the consumers are blissfully unaware of the harmful effects of these additives.

But sometimes, the level of adulteration in food crosses the threshold and then the immediate health effects are manifest as an acute public health crisis. We here describe such a tragedy from Eastern India.

\section{THE INCIDENT}

July 9, 1988. A fair price shop in Behala Buroshibtala, a suburb of Kolkata, was selling rapeseed oil. The Hindu festival of Rathyatra was coming up, and people were buying various ingredients for the upcoming festivities. The buyers were mainly the poor slum dwellers of the locality for whom rapeseed oil was an affordable medium of cooking. The name of the shop was "Garib Bhandar" (shop for the poor in Bengali). But this rapeseed oil was something special: it contained an ingredient named tri-orthocresyl phosphate (TOCP). This oil-like cheap chemical had been added to the cooking oil for a quick profit. Unknown to the poor consumers, this toxin would be entering their bodies with each cooked meal.
Department of Critical Care Medicine, Institute of Postgraduate Medical Education and Research and SSKM Hospital, Kolkata, West Bengal, India Corresponding Author: Rudrajit Paul, Department of Critical Care Medicine, Institute of Postgraduate Medical Education and Research and SSKM Hospital, Kolkata, West Bengal, India, Phone: +91 9433824341, e-mail: r.paul.medicalcollege@gmail.com

How to cite this article: Paul R. Poison in the Frying Pan. Bengal Physician Journal 2019;6(3):72-73.

Source of support: Nil

Conflict of interest: None

The effect of the poison did not manifest at first. It was only after 1 to 2 weeks that the people with a large accumulated dose of the toxin in their system started to feel its effects. Soon, the nearby Behala Vidyasagar Hospital became a battleground as a steady stream of sick patients thronged its corridors. The first symptoms started like food poisoning with vomiting and diarrhea, but it quickly escalated into ascending motor paralysis. By journalistic estimates, the number affected in Behala alone was close to 2,500. However, the official estimate of the incident put the number of those affected to around 600. Later, the official number was further reduced to around 260. Later, a second focus of the crisis was also reported from a colony in the Tollygunge area. According to the surviving victims, around 50 people had died from various complications of the poisoning. But there is no official confirmation.

Soon, adulterated rapeseed oil was found to be the culprit for these symptoms. Tri-ortho-cresyl phosphate was an ideal adulterant as its color is similar to the edible oil, and it is soluble in oil, and it does not alter the taste significantly. The level of contamination with TOCP was found to be very high: to the extent of even $57 \%$ in some of the samples. The toxicity was irreversible, and the survivors were left with permanent disability. In April 1989, a follow-up survey in two hospitals of Kolkata found about 500 people who were still undergoing treatment. Residual signs include wrist drop, foot drop, loss of grip strength, and persistent fatigue. Many had developed severe atrophy of the lower limbs. Physiotherapy and supportive orthoses were the main modes of support. Alcoholics had even less a chance of recovery.

There is not much scientific data or official document on this tragedy, and the fate of the survivors is also not recorded. There are no major research articles from Kolkata on this topic. The incident only finds a passing mention in some textbooks. 


\section{Scientific Analysis}

The poisonous chemical responsible for this "epidemic" of sudden onset motor paralysis was TOCP. This is an organophosphorus compound with anticholinesterase activity. This belongs to a large group of chemicals called tri-ortho-cresyl phosphate. The ortho isomers are thought to be more toxic than meta or para isomers. It causes a direct irreversible axonal damage of peripheral nerves.

Tri-ortho-cresyl phosphate poisoning is nothing new for mankind. In the 1930s, in the United States, during the era of prohibition, Jamaican ginger or jake, a patent medicine with $70-80 \%$ ethanol by weight, was a popular source of alcohol. In one batch of this drink, the manufacturer mixed TOCP, thinking it to be a harmless solvent. As a result, between 40,000 and 50,000 people developed lasting motor neuropathy.

Tri-ortho-cresyl phosphate is a chemical used as fire retardant, plasticizer, or lubricant. It is produced from distillation of hydrocarbons of coal tar or petroleum products. This chemical is readily absorbed through the skin or mucosa (thus, if TOCP is present in mustard oil, rubbing of oil on the skin can also cause toxicity). It is also absorbed through inhalation (during cooking, heating of oil may lead to vaporization of TOCP and absorption through the lungs). This last fact was the basis for a sensational media circus in early 2000s, when it was rumored that the cabin air in flights was likely to have TOCP vapor from leaking engine oil. The report was later debunked.

Metabolism of TOCP in liver produces highly toxic reactive compounds like saligenin cyclic-ortho-tolyl phosphate. These attack the nerves and cause "dying back neuropathy." Histology of some cases has shown axonal degeneration and degenerative changes in anterior horn cells. The effects are gradual and are called organophosphorus-induced delayed neurotoxicity. Although this is mainly a disease of peripheral nerves, sometimes delayed spinal cord degeneration has also been reported, leading to pyramidal signs. Thus, the organophosphorus effect, i.e., inhibition of AchE enzyme, has no direct role in the neural toxicity.

Usually, the symptoms start from lower limbs with muscle cramps. In a recent report from Gujarat, the main symptoms were peripheral muscular pain and mild sensory symptoms. It was followed by flaccid weakness, usually symmetrical. Many authors have reported that TOCP poisoning causes cold hands and feet. But systemic features like fever are absent. The original "Jake paralysis" of the United States also recorded that men became impotent as an aftereffect. But this symptom has not been studied in the subsequent outbreaks in India.

In the Kolkata case, the mixing of TOCP with edible oil was a deliberate act of crime. But sometimes, TOCP can get mixed with food unintentionally. For example, an outbreak in South Africa was linked to storage of potable water in drums which contained TOCP. In another case in Bengal, flour was contaminated with TOCP from a broken barrel in a ship. This flour was consumed by many people, leading to delayed manifestations of toxicity. Triortho-cresyl phosphate was used to contaminate mustard oil in Kakinara and Dumdum of West Bengal in 1968. In one interesting report from Sri Lanka in the 1970s, adolescent girls developed neuropathy after taking gingili oil contaminated with TOCP. It is a custom among Tamils of Sri Lanka to give gingelly oil to girls after menarche as nutrition. This was the reason for affection of this particular demographic group.

\section{Conclusion}

Physicians working in India must be conversant with various forms of food toxicity. Historical accounts of food toxicity must be reviewed to avoid future outbreaks.

\section{References}

1. Bhowmick A, Trends of Food Adulteration In India and Its Remedies. Project Report submitted to the FSSAI. [Internet]. [Cited 2020 Mar 09]. Available online from https://www.fssai.gov.in/upload/uploadfiles/ files/Report_Intern_Anusree_04_10_2019.pdf.

2. PTI. $68 \%$ milk \& milk products in India not as per FSSAI standard: Official. [Online]. [Updated 2018 Sep 5; Cited 2020 Mar 09]. Available online from https://economictimes.indiatimes. $\mathrm{com} /$ industry/cons-products/food/68-milk-milk-products-inindia-not-as-per-fssai-standard-official/articleshow/65689621. $\mathrm{cms}$ ?utm_source=contentofinterest\&utm_medium =text\&utm_ campaign $=$ cppst.

3. Khapre MP, Mudey A, Chaudhary S, et al. Buying practices and prevalence of adulteration in selected food items in a rural area of Wardha district: a cross-sectional study. Online J Health Allied Scs 2011;10(3):4.

4. TNN. $90 \%$ of food items tested before Diwali adulterated: Survey. The Times of India [Online]. [Published 2015 Nov 09; Cited 2020 Mar 10]. Available online from https://timesofindia.indiatimes.com/city/ dehradun/90-of-food-items-tested-before-Diwali-adulteratedSurvey/articleshow/49727805.cms.

5. Gosting DC, Doyle ME, Steinhart CE, et al. Food Safety 1990: An Annotated Bibliography of the Literature. MA: Food Research Institute, University of Wisconsin. Butterworth-Heinemann; 1991.

6. Ecobichon DJ, Joy RM. Pesticides and Neurological Diseases. 2nd ed., Florida: CRC Press; 1994.

7. Chattopadhyay D, Oil Victims Face Hungry Future. The Telegraph [Online]. [Published 2000 Dec 08; Cited 2020 Mar 10]. Available online from https://www.telegraphindia.com/india/oil-victims-facehungry-future/cid/939768.

8. de Ree $\mathrm{H}$, van den Berg M, Brand T, et al. Health risk assessment of exposure to TriCresyl phosphates (TCPs) in aircraft: a commentary. Neurotoxicology 2014;45:209-215. DOI: 10.1016/j.neuro.2014.08.011.

9. Sherk GW. Tricresyl Phosphate Neurotoxicity Potential. RISK: Health, Safety \& Environment (1990-2002). University of New Hampshire; 2000.

10. Solanki J, Patel R, Jagani DC, et al. Tricresyl phosphate (TCP) induced polyneuropathy: case series from Dehgam, Gujarat, India. Austin J Public Health Epidemiol 2017;4(1):1057.

11. Susser M, Stein Z. An outbreak of tri-ortho-cresyl phosphate (T.O.C.P.) poisoning in Durban. Br J Ind Med 1957;14(2):111-120. DOI: 10.1136/ oem.14.2.111.

12. Inoue N, Fujishiro K, Mori K, et al. Triorthocresyl phosphate poisoning-A review of human cases. J UOEH 1988;10(4):433-442. DOI: 10.7888/juoeh.10.433.

13. Chakraborty A, Mukherjee S, Chaterjee S. TOCP neuropathy: the Indian scene. Med Update 1992;2:348-355.

14. Misra UK, Kalita J. Toxic neuropathies. Neurol India 2009;57(6): 697-705. DOI: 10.4103/0028-3886.59463.

15. Senanayake N. Tri-cresyl phosphate neuropathy in Sri Lanka: a clinical and neurophysiological study with a three year follow up. J Neuro Neurosurg Psychiat 1981;44(9):775-780. DOI: 10.1136/jnnp.44.9.775. 